\title{
El turismo residencial en Malinalco Un destino rural del interior de México
}

\author{
Vanessa Alicia Escobedo Ildefonso* \\ Maribel Osorio García \\ Irma Cortés Soto \\ Facultad de Turismo y Gastronomía \\ Universidad Autónoma del Estado de México \\ Álvaro López López \\ Instituto de Geografía \\ Universidad Nacional Autónoma de México
}

\section{Resumen}

La presente investigación expone el resultado de un estudio diacrónico sobre la evolución de los componentes de oferta y demanda del turismo residencial en Malinalco, Estado de México y los impactos que se manifiestan en una segunda fase de su desarrollo, pues se trata de un destino turístico para nacionales que registra un comportamiento migratorio y de mercado muy diferente del modelo dominante del turismo residencial de la costa, conformado mayormente por flujos internacionales. Se comparan los rasgos de este tipo de turismo en el 2004 y en el 2014, develándose el patrón prevaleciente, los cambios ocurridos y las tendencias previstas para la siguiente década.

\section{Palabras clave}

Turismo residencial, segundas residencias, impactos, Malinalco.

Recibido: 14/07/2014 · Aceptado: 11/08/2014

*Correo electrónico: vann.lestrange@gmail.com; maribelosorio2@gmail.com; iycortes@yahoo. com.mx; lopuslopez@igg.unam.mx 


\title{
Residential tourism in Malinalco
}

A rural destination in Mexico

\author{
Vanessa Alicia Escobedo Ildefonso* \\ Maribel Osorio García \\ Irma Cortés Soto \\ Facultad de Turismo y Gastronomía \\ Universidad Autónoma del Estado de México \\ Álvaro López López \\ Instituto de Geografía \\ Universidad Nacional Autónoma de México
}

\begin{abstract}
The present research concerns the result of a diachronic study on the evolution of the supply and demand components of residential tourism in Malinalco, State of Mexico State and the impacts that are manifested in a second phase of its development. It is a destination for domestic tourism that has a very different migratory and market behavior when compared to the dominant model of coastal residential tourism, which is composed mostly of international capital flows. A comparison between the traits of this type of tourism in 2004 and 2014 shows the prevailing pattern, changes and trends that are expected for the next decade.
\end{abstract}

\section{KEY WORDS}

Residential tourism, second homes, impacts, Malinalco.

*E-mail: vann.lestrange@gmail.com; maribelosorio2@gmail.com; iycortes@yahoo.com.mx; lopuslopez@igg.unam.mx 


\section{Introducción}

La modalidad de turismo residencial (тR) es un tema emergente en la investigación turística, cuyo interés ha ido incrementándose debido a la también creciente manifestación de este tipo de turismo en muchos lugares del mundo, no solo en los países desarrollados, sino también, con formas particulares, en aquellos en desarrollo. Una interesante revisión del estado de la cuestión sobre el TR es la elaborada por Huete y Mantecón (2012), en la que distinguen los rasgos más sobresalientes de este fenómeno: el proceso migratorio internacional, la especulación inmobiliaria, el perfil del turista/migrante, así como los impactos económicos, sociales y ambientales que se generan en los destinos. El aspecto recurrente en el estudio del tema es el relativo al proceso migratorio internacional (Benson y O’Reilly, 2009; Hall y Müller, 2004; Müller, 2002; Rodríguez, 2004; Williams y Hall, 2000) que señala la movilidad del norte al sur de Europa (Casado-Díaz, Kaiser y Warnes, 2004) y el enfático perfil de jubilados que tienen los turistas residenciales (Coles, Duval y Hall, 2005; O’Really y Benson, 2009; Sanz, 2008). Otro ámbito de investigación es el referente a su manifestación como mercado inmobiliario (Warnken y Guilding, 2009) y a sus efectos sociales y políticos (Faulkenberry et al., 2000; O’Reilly, 2007). Es por ello que también se han realizado esfuerzos por profundizar en su medición estadística (Varela, López y Martínez, 2003) y en su análisis teórico (Guilding et al., 2005).

Mención especial merece la producción científica que aborda el caso de España y de su costa mediterránea, pues, además del tratamiento migratorio europeo norte-sur (Alarcón, González y Pérez, 2010; López de Lera, 1995; Huete y Mantecón, 2010; Nielsen, 2009; O’Reilly, 2009), hay una amplia investigación sobre el tema inmobiliario y de la vivienda de segunda residencia (SR) vinculada con los conflictos territoriales por la apropiación y saturación del espacio (Almeida y López, 2003; Díaz y Lourés, 2006; Fernández y Barrado, 2011; García, Artal y Ramos, 2002; Gili, 2003; Mazón, 2006; Martínez, Pauls y Solsona, 2003; Serrano Martínez, 2003) y diversas aproximaciones a los impactos territoriales y sectoriales generados por esta modalidad turística y sus consecuencias sobre el paisaje (Aledo, García y Ortiz, 2010; Aledo, 2008; Torres, 2003). Un elemento adicional sobre los estudios realizadas en esta región es el concerniente a las actitudes y opiniones de la población originaria de los destinos turísticos en las comunidades receptoras respecto de las segundas residencias (Huete, 2010; Mantecón y Huete, 2011; Mazón, Huete y Mantecón, 2009). 
Dada esta riqueza temática, existe también el cuestionamiento a sus posiciones teórico-conceptuales (Huete, Mantecón y Mazón, 2008; Aledo, Mazón y Mantecón, 2007; Mazón, 2006) y a sus posibles tendencias de desarrollo (Huete, 2008; Salvà, 2011).

En Latinoamérica, diversos temas de las sR (la inmigración norteamericana, la expansión inmobiliaria y las repercusiones) son retomados en México por Hiernaux (en la investigación dirigida por él en coordinación con el Centro de Estudios Superiores en Turismo de la Secretaría de la Turismo, Cestur-Sectur, 2004 y en Hiernaux, 2005, 2009 y 2010), la Fundación BBva Bancomer (2012), Lizárraga (2010) y Palma (2005); en Chile por Hidalgo y Zunino (2011), y en Centroamérica por Cañada (2010) y Van Noorloos (2009), entre otros.

Como se observa, buena parte de la investigación se ha centrado en el fenómeno migratorio internacional que ha generado grandes expansiones urbanas y procesos distintos de apropiación del suelo y de los recursos de los destinos receptores, con repercusiones ambientales, económicas, políticas y sociales particulares derivadas de la inserción temporal de extranjeros jubilados -principalmente- en zonas costeras. Sin embargo, son aún escasos los trabajos que ilustran el fenómeno del TR como parte del turismo doméstico y menos todavía los que se refieren a destinos del interior, cuyos rasgos difieren tanto en motivaciones como en patrones de viaje e impactos.

Una importante aproximación a las distintas expresiones del tR es la realizada por Hiernaux (Cestur-Sectur, 2004) para el caso de México, en ella propone una tipología de modelos de TR que obedecen justamente a un cruce de criterios de localización (costa/interior) y de origen del turista residencial (extranjero/ nacional). El citado autor indica que dicho fenómeno inició en México desde los años cuarenta y poco a poco se ha ido extendiendo hasta alcanzar una cifra estimada de 600000 viviendas para el 2004; y aunque esta cifra solo representaba $3 \%$ del total de viviendas en el país, su presencia era muy significativa en algunas regiones (Cestur-Sectur, 2004: 100).

De hecho, de acuerdo con la estimación del número de cuartos por destino, se identificaron 85344 cuartos localizados en ocho centros costeros de México: Acapulco, Cancún-Riviera Maya, Manzanillo, Mazatlán, Puerto Peñasco, Puerto Progreso, Puerto Vallarta y el corredor Tijuana-Rosarito-Ensenada; y 131 145 cuartos en centros del interior: Chapala, Ixtapan de la Sal, Malinalco, San 
Miguel de Allende, Tequisquiapan y Valle de Bravo (Cestur-Sectur, 2004: 100). Estas cifras revelan que $60 \%$ de los cuartos de sR se ubicaba en destinos del interior contra $40 \%$ en destinos de playa, lo que da cuenta del predominio de una movilidad interior, claramente diferenciada del fenómeno de inmigración internacional que, entre otros, ha caracterizado el TR en España.

Los destinos más densificados del interior de México son, sin duda, el estado de Morelos, en especial en Cuernavaca, Tepoztlán, Tlayacapan, Jojutla y Tequesquitengo, región que en su conjunto presenta la mayor concentración de vivienda de segunda residencia en el país (100 000 cuartos estimados); le sigue el Estado de México, con tres poblaciones que registran esta modalidad: Valle de Bravo, Malinalco e Ixtapan de la Sal. En ambos estados, las sR son un fenómeno de movilidad generado por el turismo doméstico, su amplio crecimiento es producto del flujo de nacionales que viven en las zonas metropolitanas del valle de México y de Toluca -con una población total calculada en 22 millones de habitantes para el 2010 (Conapo, 2012)- y cuyos residentes se desplazan en viajes reiterados al entorno rural.

Tanto las localidades mencionadas del estado de Morelos como la de Valle de Bravo se consideran destinos maduros de TR, cuyo detonador inmobiliario se registró entre las décadas de 1970 y 1980; no obstante, Malinalco es un destino en crecimiento, que se inicia a partir de la década de los años noventa, lo cual permite observar de mejor manera su proceso de desarrollo, a la vez que las transformaciones espaciales y sociales que va originando, por esta razón, el objetivo del presente artículo es analizar la evolución de los componentes de la oferta y demanda del TR en Malinalco, para detallar la forma particular en la que se comporta esta modalidad conformada por un turismo doméstico.

El texto se estructura en seis apartados: un marco conceptual en el que se precisan los términos de TR, sus modalidades, componentes y fases de evolución; en segundo lugar se ofrece el contexto, en el que se caracteriza física, social y económicamente a Malinalco; después se exponen información y datos sobre la situación turística del municipio; a continuación se hace el planteamiento metodológico sobre el que se sustenta la investigación, y se describen las técnicas de campo utilizadas; el quinto apartado incluye los resultados del estudio del TR en el destino, de acuerdo con las fases de evolución planteadas en el marco teórico, así como los impactos económicos, ambientales y socioculturales que han 
repercutido en la localidad; por último, se integran las conclusiones en torno al caso de estudio como modalidad del TR del interior del país.

\section{Marco conceptual}

Turismo residencial es un concepto problemático, como lo han sostenido varios investigadores (Williams y Hall, 2000; Huete, Mantecón y Mazón, 2008), tanto por su débil frontera con el concepto de migración, como por la diversa temporalidad en la que ocurre, llegando incluso a diluirse con una "vida cotidiana" en residencias permanentes (Huete y Mantecón, 2010). En esta investigación se parte de la distinción que ha hecho Huete (2008) para enmarcar el concepto desde dos perspectivas: el de la demanda y el de la oferta. El primero ha sido el más recurrente, puesto que para su caracterización se han tomado los estilos de vida y las prácticas de viaje de los turistas (Raya Mellado, 2001: 494; McWatters cit. en Aledo, García y Ortiz, 2010: 3; Torres, 2003: 47; Ramón y Taltavull, 2005: 68; Salvà, 2005: 282), aludiendo al TR como una tipología de turistas, una demanda o flujo de personas, por lo general agrupadas en unidades familiares, que relocalizan su vivienda en alojamientos no reglamentados, en destinos diferentes de los de su residencia habitual, por periodos de estancia variables y con motivaciones que no se relacionan con factores laborales.

En la perspectiva de la oferta (Aledo, 2008: 3; Mazón y Aledo, 2005: 18-19; Salvà, 2005: 282) se le define como una actividad económica e inmobiliaria, señalando que la compra de suelo, la construcción y venta de viviendas para alojamiento extrahotelero, así como la creación de infraestructura y dotación de servicios, generan un proceso de urbanización que afecta las estructuras económicas, sociales y ambientales de los destinos. Sin duda ambos enfoques son complementarios y convergen en elementos estructurantes del concepto: el flujo de los usuarios, los alojamientos extrahoteleros, las motivaciones de ocio, la variación temporal de la residencia, etcétera.

Para el caso que nos ocupa, es importante recuperar la precisión que hace Hiernaux sobre la denominación de "oferta” en el tr para el caso de México, puesto que si ésta se adopta se asumiría que las SR son edificadas para ser puestas en el mercado, pero no es así: "una gran mayoría de éstas fueron construidas por el mismo dueño para su uso personal familiar y sólo serán puestas en 
el mercado si alguna situación particular lo obliga [a venderla]" (Cestur-Sectur, 2004: 42). En consecuencia, y pese a que su utilización resulta funcional, el término oferta no es apropiado del todo ya que la gran mayoría de las viviendas de segunda residencia se consideran más un bien de uso que uno de cambio. Asimismo, el mercado de las SR no se comporta como un mercado formal, debido a que una proporción significativa está fuera de la esfera mercantil empresarial, en virtud de que los viajes se hacen a la casa propia o de los amigos o familiares y, eventualmente, a casas rentadas, pero, casi siempre, por transacciones directas, fuera del mercado "habitual".

A pesar del dominio de la casa privada como segunda residencia, se reconoce que el sector inmobiliario ha ido penetrando de manera paulatina en este segmento de negocio, a través de la construcción de viviendas en fraccionamientos o de vivienda en integración vertical. La tipología de SR expuesta por Hiernaux (Cestur-Sectur, 2004: 50) facilita comprender la composición de la "oferta" de TR en México: viviendas unifamiliares independientes, las cuales sin duda han sido las predominantes y que han seguido patrones como la compra de casas tradicionales e históricas y de autoconstrucción de casas nuevas; un segundo tipo son los inmuebles individuales en fraccionamiento y construidos por un promotor; y por último los departamentos en edificios de tipo multifamiliar, derivados en buena medida de la vivienda de interés social en los destinos de playa, como es el caso de Acapulco.

La perspectiva de esta investigación es precisamente la de Hiernaux, que define al TR como "aquel por el cual las personas acuden a un destino o una localidad que no es forzosamente turística per se, donde tienen la posesión por compra, renta o préstamo de un inmueble en el cual pernoctan y realizan actividades de ocio y esparcimiento" (Cestur-Sectur, 2004: 9). Así, el autor establece dos diferencias respecto de los anteriores: en primer lugar, resalta la condición de que el destino no necesariamente es turístico, aunque las motivaciones de la estadía sí correspondan al ocio; y, en segundo, no menciona la dimensión de la temporalidad, en la que las definiciones de autores anglosajones y españoles han hecho especial énfasis, dada la particularidad de sus flujos migratorios internacionales. Ambos elementos quedan abiertos para ser tratados en la tipificación de las modalidades de sR en México que realiza el autor (Cestur-Sectur, 2004: 183), producto de la diversidad de prácticas encontradas en el país en sus distintas investigaciones (Hiernaux, 2005, 2009 y 2010): 
a) Modelo de playa masificada a dominante nacional, cuya demanda principal es la doméstica con SR de veraneo.

b) Modelo costero con fuerte presencia extranjera, en la que se observan los patrones de migración internacional y las prolongadas estancias residenciales.

c) Modelo de interior con atractivo turístico y dominante residencial, donde el flujo se realiza en regiones del interior del país cuya afluencia puede ser nacional y/o extranjera.

d) Modelo de interior masivo, con un amplio volumen de afluencia de turistas domésticos a destinos del interior, en esencia a casas de fines de semana.

El caso que resulta de interés en esta investigación es el modelo de interior con atractivo turístico y dominante residencial, al cual responde Malinalco, pues es un sitio que se ha consolidado en torno a atractivos culturales. Hiernaux resalta una particularidad que distingue la práctica del viaje en esta modalidad: los turistas residenciales no suelen visitar con frecuencia los destinos de interés cultural y toman una actitud pasiva o de conservación con respecto a ellos, a diferencia de los destinos consolidados por atractivos naturales en los cuales los turistas disfrutan activamente de estos. Así, el autor afirma que los turistas residenciales se insertan en el lugar por el valor de los atributos culturales, y por las características del paisaje y clima de la localidad, circunscribiendo su estancia a la convivencia familiar y/o social (relaciones de amistad o profesionales) (Cestur-Sectur, 2004: 183-184).

Cabe aclarar que el segmento de población que compone el grueso de la demanda del TR en México proviene de estratos socioeconómicos medios, altos y muy altos, cuyos niveles de ingreso se ubican en los grupos A/B, C y C + , ya que deben poder solventar tanto la adquisición de la vivienda, como su mantenimiento básico (limpieza y jardinería), sus reparaciones mayores y el pago de impuestos y servicios de infraestructura necesarios (luz, agua y predial).

En el caso del modelo comentado, se considera que el patrón de comportamiento manifiesta un significativo repliegue en la vivienda residencial para el cumplimiento del imaginario del disfrute de la paz y el reposo en el campo (Urbain, 2002), lo que propicia un mayor aislamiento en las casas y una menor interacción con la comunidad del destino. 
Un elemento adicional que se desea establecer en este apartado es la caracterización que realizan Williams y Hall (cit. en Huete, Mantecón y Mazón, 2008) respecto de las fases que sigue la evolución de un destino de TR de acuerdo, sobre todo, con la experiencia europea: la primera fase tiene que ver con el descubrimiento del destino, en ella llega un primer flujo de turistas para iniciar esta modalidad en el lugar; una segunda fase muestra el proceso de masificación del TR producido por el incremento de la demanda, aún en una condición de "veraneo"; en la tercera fase los flujos turísticos se vuelven migratorios ante la elección de los turistas de residir de forma permanente o temporal en el destino.

Como puede observarse en la evolución descrita, el criterio clave es el cambio de un flujo turístico a un flujo migratorio, a partir del comportamiento de la demanda, sin embargo, en el caso de México y desde un enfoque de oferta, dadas las peculiaridades expuestas, el criterio fundamental de la evolución parecería depender de la consolidación progresiva de un mercado inmobiliario formal, en el que la primera etapa se distingue por la prevalencia de las casas individuales autoconstruidas o compradas directamente por particulares; la segunda por el paulatino crecimiento de un mercado inmobiliario de casas en fraccionamientos, y la tercera aquella en la que los agentes inmobiliarios dominan tanto la venta de casas individuales como la construcción y comercialización de viviendas en fraccionamiento y en condominio. Para efectos de la presente investigación, denominaremos a la primera fase como "el descubrimiento", a la segunda "el despegue" y a la tercera "la madurez".

En nuestra interpretación, los impactos del tr en el destino se advierten desde la segunda fase del ciclo, en la cual se aprecian las primeras transformaciones generadas por esta modalidad turística: la dinamización de la industria de la construcción; el aumento del empleo temporal; el cambio de uso de suelo; el incremento de precio de los terrenos; la mayor recaudación fiscal; la inflación en diversos bienes y servicios (alimentos, por ejemplo); el debilitamiento de la actividad agropecuaria por el crecimiento del sector terciario; la participación de los turistas residenciales en la protección al ambiente, en el cuidado del patrimonio y en las acciones de desarrollo social en las que se involucran; entre otros. 


\section{El contexto de Malinalco, Estado de México}

Malinalco es una localidad enclavada en la parte rural del sur-suroeste del Estado de México y funge como cabecera del municipio del mismo nombre (mapa 1). El clima semicálido subhúmedo del municipio (con $11.6 \%$ de lluvias) favorece una temperatura media anual de $20.2^{\circ} \mathrm{C}$ con máximas en verano de $23.5^{\circ} \mathrm{C}$ y mínimas en invierno de $17.1^{\circ} \mathrm{C}$, por lo que su temperatura es muy agradable prácticamente durante todo el año (GEM, 2009: 8).

La comunidad se asienta en un valle a $850 \mathrm{msnm}$ y está enmarcada por una serranía del lado oeste que asciende hasta los $2600 \mathrm{msnm}$, lo que permite encontrar una vegetación de bosque de pino-encino en la parte alta, que contrasta con la selva baja caducifolia de la parte baja. La cruzan diversos ríos y el agua es abundante en ciertas zonas, en particular en la parte baja donde se registra una amplia variedad de árboles frutales y de otras especies (amate amarillo, guajes y jacarandas), que era usual encontrar en los jardines o traspatios de las casas tradicionales. No obstante, hay escasez de agua en las partes altas, donde las corrientes subterráneas la conducen hasta el valle.

El interés por preservar los valiosos ecosistemas que existen en el municipio ha propiciado su inclusión en distintas áreas naturales protegidas, entre ellas el Parque Ecológico y Recreativo Tenancingo, Malinalco y Zumpango y el Parque Natural Nahuatlaca- Matlazinca (mapa 1).

Lo que atrae a los turistas a Malinalco no es solo su riqueza natural, sino también y sobre todo la cultural. En la época prehispánica fue asiento de las culturas teotihuacana, tolteca, matlazinca y azteca. De las dos últimas existe un sitio arqueológico monolítico, ubicado en la cima del cerro de los ídolos, lugar al que acudían los caballeros águilas aztecas a realizar ritos para su iniciación como guerreros (GEm, 1999). En el siglo xv Malinalco fue colonizado por los españoles y dado en encomienda a Cristóbal Rodríguez, quien en 1543 mandó construir la capilla de Santa Mónica y el templo del Divino Salvador con su convento anexo (ahora exconvento de la Transfiguración), decorado con lienzos y pinturas al fresco que aún se conservan (Shneider, 1999: 97). De aquí el sincretismo religioso que perdura en la población y que se manifiesta en prácticas y festividades frecuentes en los tradicionales barrios.

Según el Censo General de Población y Vivienda 2010 (inegi, 2010), el municipio de Malinalco tenía una población urbana de 10688 habitantes (41.71\%) 


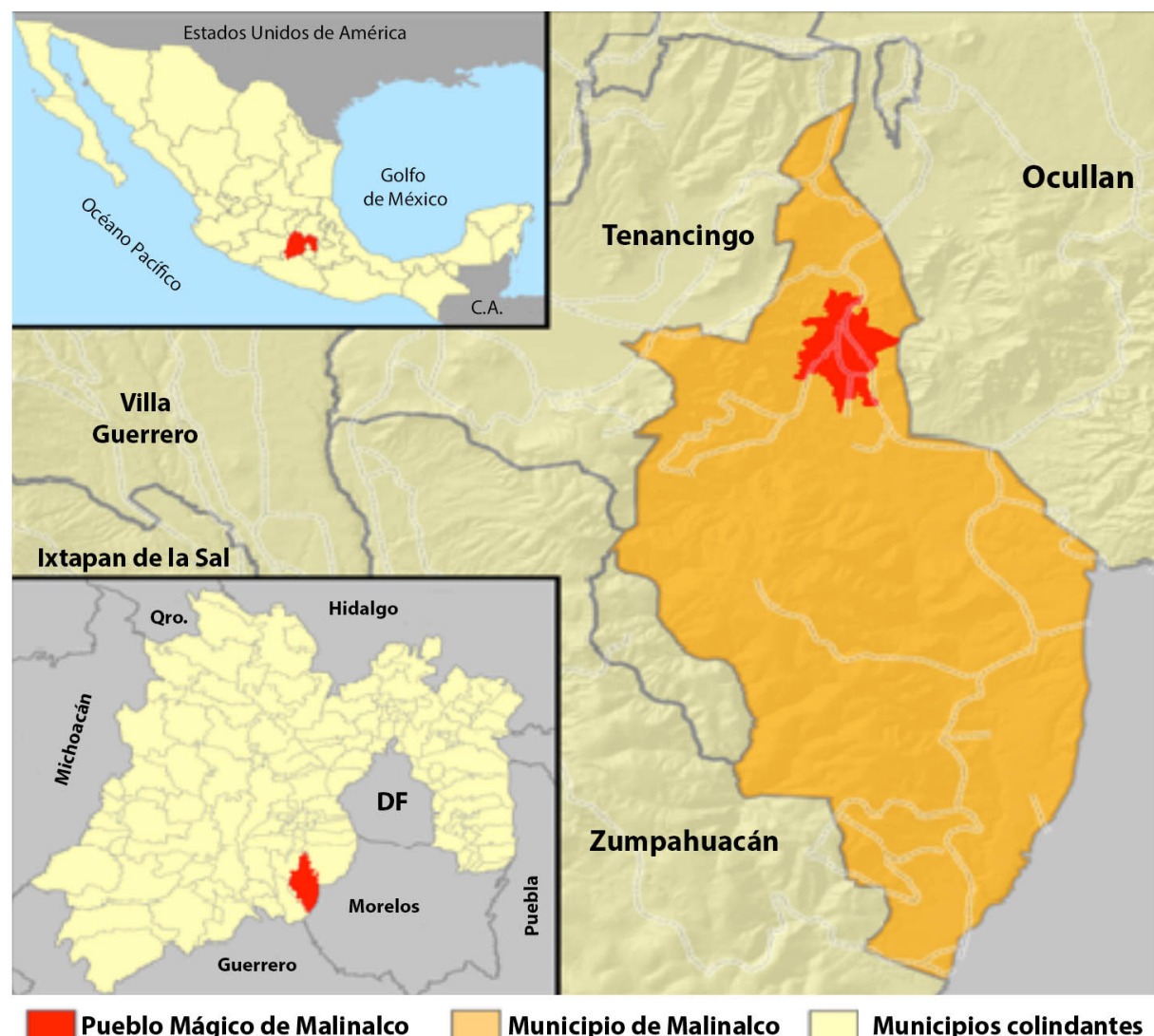

MAPA 1. Localización de Malinalco, Estado de México

y una rural de 14936 (58.29\%), por lo que se considera uno de los municipios rurales del Estado de México. Sus circunstancias son representativas de muchos municipios rurales del país: población mayoritariamente en situación de pobreza, bajos niveles de desarrollo y altos índices de rezago social. De hecho, los indicadores de rezago social son superiores a los de la media estatal y nacional, a excepción del relativo a la carencia de acceso a los servicios de salud, en el que su condición es menos crítica (cuadro 1). 
CUADRo 1. Medición de la pobreza en el municipio de Malinalco, Estado de México (2010)

\begin{tabular}{|c|c|c|c|}
\hline INDICADORES & $\begin{array}{l}\text { PORCENTAJE } \\
\text { MUNICIPAL }\end{array}$ & $\begin{array}{l}\text { PORCENTAJE } \\
\text { ESTATAL }\end{array}$ & $\begin{array}{l}\text { PORCENTAJE } \\
\text { NACIONAL }\end{array}$ \\
\hline Población en situación de pobreza & 66.0 & 34.8 & 46.2 \\
\hline $\begin{array}{l}\text { Población en situación de pobreza } \\
\text { extrema }\end{array}$ & 20.2 & 8.2 & 10.4 \\
\hline Rezago educativo & 32.5 & 18.5 & 20.6 \\
\hline Carencia de acceso a los servicios de salud & 22.9 & 35.5 & 31.8 \\
\hline Carencia de acceso a la seguridad social & 82.0 & 58.9 & 60.7 \\
\hline $\begin{array}{l}\text { Carencia de acceso a la calidad y espacios de } \\
\text { la vivienda }\end{array}$ & 20.5 & 12.9 & 15.2 \\
\hline $\begin{array}{l}\text { Carencia de acceso a los servicios básicos en } \\
\text { la vivienda }\end{array}$ & 44.4 & 13.3 & 16.5 \\
\hline Acceso a la alimentación & 44.5 & 31.6 & 24.9 \\
\hline
\end{tabular}

Fuente: Elaboración propia con base en los datos del Coneval, 2010.

Con relación al rezago educativo, los datos del nivel de instrucción indican que $14.3 \%$ de la población tiene concluida la primaria, $16.1 \%$ la secundaria y 10.4 \% la educación media superior o superior, lo cual significa un aumento de tan solo $6 \%$ en la última década para los dos últimos niveles (INEGI, 2000 y 2010). Lo anterior repercute desfavorablemente en las posibilidades de empleo e ingresos.

En correspondencia con el índice de carencia de acceso a los servicios básicos de la vivienda, en 2010 se reportó que de un total de 6104 viviendas, $19.17 \%$ carecía de agua y $23.48 \%$ de drenaje (GEM, 2012: 68), pero además otros rubros también se manifestaban deficitarios, por ejemplo, de un total de 4958 viviendas, 20 \% carecía de sanitario y $20 \%$ de piso de cemento, mosaico u otro (INEGI, 2005).

Es importante resaltar que la estructura económica del municipio ha cambiado en la última década. Para el año 2000, la principal actividad económica aún era el sector primario, para 2010 ya era el sector servicios, contribuyendo con $63 \%$ de las unidades económicas y 48 \% de la población económicamente 
activa ocupada (PEAO), hecho que implica un desplazamiento de las actividades agrícolas y una clara señal del proceso de terciarización de la economía en este municipio (GEM, 2013; GEM, 2012: 138).

Por consiguiente, se ha registrado una disminución progresiva en el porcentaje de población que se dedica a las actividades primarias, pasando de $56 \%$ de PEAO en el 2000 a $31 \%$ en el 2010, lo que se traduce en el abandono de la agricultura y la ganadería y en las consecuentes formas tradicionales de autosuficiencia. Se nota además un ligero incremento de la participación femenina en la población económicamente activa (PEA), pasando de $22.5 \%$ en el 2000 a $25.4 \%$ en el 2010 (INEGI, 2000 y 2010).

Un indicador adicional de esta reestructuración económica se ilustra con el comportamiento del producto interno bruto (РІВ) municipal, el cual se concentra en esencia en tres ramas: el comercio (38.1\%); los servicios de esparcimiento, culturales y deportivos y otros servicios recreativos (25.40\%); y los servicios de alojamiento temporal y de preparación de alimentos y bebidas (20.60 \%) (GEM, 2012). Estos datos evidencian con nitidez su conexión con el sector turismo, básicamente con el llamado turismo convencional.

En apariencia, la población se ha visto beneficiada con este cambio económico ya que, en el año 2000, 17.4 \% de la población obtenía más de dos salarios mínimos, cifra que aumentó a 30.4 \% en el 2010 (GEM, 2012). Sin embargo, esta cantidad contrasta con el incremento de la tasa de desempleo que pasó de 1.0 en el 2000 a 4.4 en el 2010 (INEGI, 2000 y 2010). Se estima, entonces, que ni el crecimiento en el ingreso ni el cambio de estructura económica han sido suficientes para generar mejores condiciones de vida a la mayoría de la población, pues el nivel de pobreza que presenta $(66 \%)$ y su grado de intensidad migratoria (0.61, lo que se considera alto) en busca de superiores oportunidades de empleo e ingreso son consecuentes con el grado de marginación medio en el que se clasifica a Malinalco (GEM, 2012: 71).

\section{El turismo en Malinalco}

En materia de turismo, Malinalco ha tenido tres detonantes que han estimulado la corriente de visitantes: el primero fue en la década de los ochenta, cuando se mejora el acceso a la zona arqueológica y se crea una piscicultura para el cultivo de trucha, constituyéndose en los atractivos más destacados del lugar; 
el segundo fue la construcción en 1993 de la carretera que conectó a Toluca con el Distrito Federal, con motivo del desarrollo del Club de Golf Malinalco, lo que impulsó fundamentalmente la modalidad del TR; el tercero corresponde al nombramiento de la localidad como Pueblo Mágico en 2010, bajo el programa promovido por la Secretaría de Turismo federal para la mejora de la infraestructura, el equipamiento, la imagen urbana y el producto turístico, además de los apoyos promocionales y de marca que conlleva.

Estas acciones han ubicado a Malinalco entre los destinos más visitados en el Estado de México y han acentuado su cariz turístico, así lo revela el paulatino crecimiento de la oferta hotelera y restaurantera que, para el 2014, tiene registradas 272 habitaciones en 31 establecimientos de diferentes tipos y categorías (ocho de 5 estrellas, dos de 4 estrellas, tres de 3 estrellas, dos de 2 estrellas, cuatro de 1 estrella, cuatro cabañas, cuatro posadas, tres casas y un hotel boutique); y 32 restaurantes de calidad turística con capacidad para 2808 personas (Sectur, 2014). Se calcula además que el sector turístico convencional emplea alrededor de 165 personas en trabajos permanentes, más los empleos indirectos y temporales requeridos para atender el incremento estacional de visitantes (GEM, 2013).

La Secretaría de Turismo estatal (Sectur, 2012) reportó que en 2011 se registró una cantidad aproximada de 800000 visitantes, de los cuales se calcula que $25 \%$ son turistas, es decir, visitantes que pernoctaron en la localidad al menos una noche. El gasto per cápita promedio de turistas se estimó en 2218 pesos.

La corriente recreativo-turística de Malinalco se ubica en cuatro segmentos: los turistas de altos ingresos que visitan la zona arqueológica y se hospedan para luego seguir su ruta hacia Cuernavaca o Taxco, o regresar a su destino; los visitantes de ingresos económicos medios o bajos, que acuden al sitio por la tradición de las truchas y la visita al centro religioso en Chalma, localizado a 12 minutos del poblado; los individuos cuyos padres, o ellos mismos, son originarios de Malinalco, pero residen en otro estado o país, por haber migrado en búsqueda de mejores condiciones de vida; y los turistas residenciales o de SR; este último representa $10 \%$ del total de la demanda turística del municipio (Cestur-Sectur, 2004).

Lo que más se acostumbra en el destino es la visita por horas, ya sea para recorrer los sitios de interés cultural o simplemente disfrutar su clima y sus pla- 
tillos típicos, aunque la pernocta es una práctica consolidada en el segmento de altos ingresos, pues en términos de hotelería se dispone de ocho establecimientos de máxima categoría. Como se expuso en el apartado anterior, esta actividad está estructurando la dinámica económica del municipio y está modificando su composición sectorial; sin embargo, la modalidad del TR, cuya participación en la actividad turística parecería ser mínima, tiene la capacidad de transformar en mayor medida el consumo del espacio urbano de la localidad y con ello producir una serie de efectos ambientales y sociales en su comunidad.

\section{Metodología}

De acuerdo con el objetivo del presente artículo, se estudiará la evolución de la oferta y la demanda del TR en Malinalco para dilucidar los patrones que adopta de esta modalidad y delinear sus efectos particulares. En consecuencia, se llevará a cabo un análisis diacrónico de las características registradas en este destino al comparar la condición de la oferta y la demanda entre el 2004 y el 2013, así como la situación de los impactos derivados directamente del TR.

Por lo que toca a la oferta, en virtud de que la información estadística sobre SR es prácticamente inexistente, se efectuó una aproximación general a través de tres elementos:

- Estimar el volumen de unidades actuales para obtener un comparativo que permitiera calcular su tasa de crecimiento.

- Identificar su actual distribución territorial a fin de conocer su patrón de ubicación con respecto a la estructura urbana de Malinalco.

- Establecer una relación entre las viviendas totales y las sR, para identificar su proporción respecto de las viviendas propiamente locales.

Esta información se obtuvo a través del levantamiento de un inventario en campo de las SR realizado durante los meses de septiembre a diciembre del 2013 y de cinco entrevistas a autoridades municipales y personas clave de la comunidad.

Con relación a la demanda, para la comparación contra los datos de 2004, se requirió trabajo de campo y el diseño de un cuestionario ex profeso con preguntas abiertas y cerradas, el cual se elaboró a partir de tres categorías de análisis: 
perfil socioeconómico, comportamiento de viaje e impactos. Se presentan a continuación las variables de análisis para cada categoría:

Cuadro 2. Variables de análisis del perfil del turista residencial en Malinalco

\begin{tabular}{ll}
\multicolumn{1}{c}{ Perfil socioeconómico } & \multicolumn{1}{c}{ Comportamiento de ViaJe } \\
$\cdot$ Edad & - Temporada en que hace uso \\
- Sexo & de la residencia \\
$\cdot$ Estado civil & Acompañantes \\
$\cdot$ Nacionalidad & Motivo de la visita \\
$\cdot$ Lugar de residencia & - Frecuencia de la visita \\
$\cdot$ Ocupación del jefe de familia & $\cdot$ Actividades que realiza \\
$\cdot$ Ingreso familiar & $\cdot$ Gasto promedio familiar \\
& Impactos \\
$\cdot$ Empleos: número, contrataciones, prestaciones, origen, actividades, salarios \\
$\cdot$ Apertura de negocios
\end{tabular}

Fuente: Elaboración propia.

Posterior a la prueba piloto, el cuestionario definitivo solo se pudo aplicar a 22 turistas residenciales. La razón de tan escaso número obedece al nivel de rechazo encontrado en los sujetos por revelar información sobre su nivel económico y su patrimonio, derivado del ambiente de inseguridad prevaleciente en México. Entonces, los resultados se presentan como un sondeo que no es estadísticamente representativo, pero que sí desvela el patrón de comportamiento de este tipo de visitante.

Por último, se hizo una identificación de impactos fundamentalmente económicos: costo del suelo, empleo, diversificación y especialización económica, derrama económica y encarecimiento de la vida; aunque también se pudo distinguir algunas repercusiones ecológicas y sociales. Esto se obtuvo gracias a las entrevistas a personas clave y al sondeo aplicado a los turistas residenciales. 


\section{La evolución del tr en Malinalco}

Primera fase: el descubrimiento

La identificación más certera de la existencia de casas de segunda residencia en Malinalco se ubica en la década de los setenta, cuando se recuerda la existencia de al menos 12 casas de sR en esta localidad rural, cuyo agradable clima y paisaje pintoresco atrajo a un flujo inicial de turistas. El lento crecimiento continuó durante los años ochenta, periodo en que se logran distinguir unas 40 casas de sR, localizadas sobre todo en el interior de la traza urbana original, aunque algunas otras empezaron a construirse en la periferia, por el requerimiento de espacios más amplios para la edificación de las residencias.

Aunado al flujo turístico tradicional que empieza a crecer en esta población, el TR se detona en su primera fase en los años noventa, ya que entre 1992 y 1993 se construye y abre la nueva carretera hacia la cabecera municipal y se crea el Club de Golf Malinalco, complejo situado en el barrio de San Sebastián, a $4 \mathrm{~km}$ del poblado, donde se ofertaron 483 lotes familiares en una superficie de 200 ha. Desde entonces, el poblado optimizó su privilegiada localización, ya que se sitúa a $95 \mathrm{~km}$ de la capital del país (GEM, 2009). El mencionado club de golf inició un proceso de desarrollo inmobiliario en el lugar, aunque de manera aislada respecto de la localidad, creando desde ese momento un enclave en el sitio. Cabe destacar que la instalación del club fue motivo de protestas por parte de los pobladores, en particular por la escasez de agua, pues les afectaría el volumen DFR la dotación del líquido.

Los informantes clave comentaron que, además del clima y el paisaje pintoresco del poblado, el crecimiento paulatino de las sR fue motivado por la peculiaridad de que los turistas residenciales que se instalaron tenían el perfil de intelectuales (como el destacado literato mexicano, doctor Luis Mario Schneider) y de políticos (como el maestro en Filosofía José Córdoba Montoya, jefe de la Oficina de la Presidencia durante el mandato de Carlos Salinas de Gortari). Por ende, Malinalco adquirió fama entre distintos círculos de élite, revelándose como una oportunidad para adquirir terrenos y construir una casa de campo cercana a la zona urbana de residencia habitual (a semejanza de personajes distinguidos). Esta característica atrajo a un perfil de turista residencial que se identificó con lo culto, lo rural, lo privado y lo selecto. 


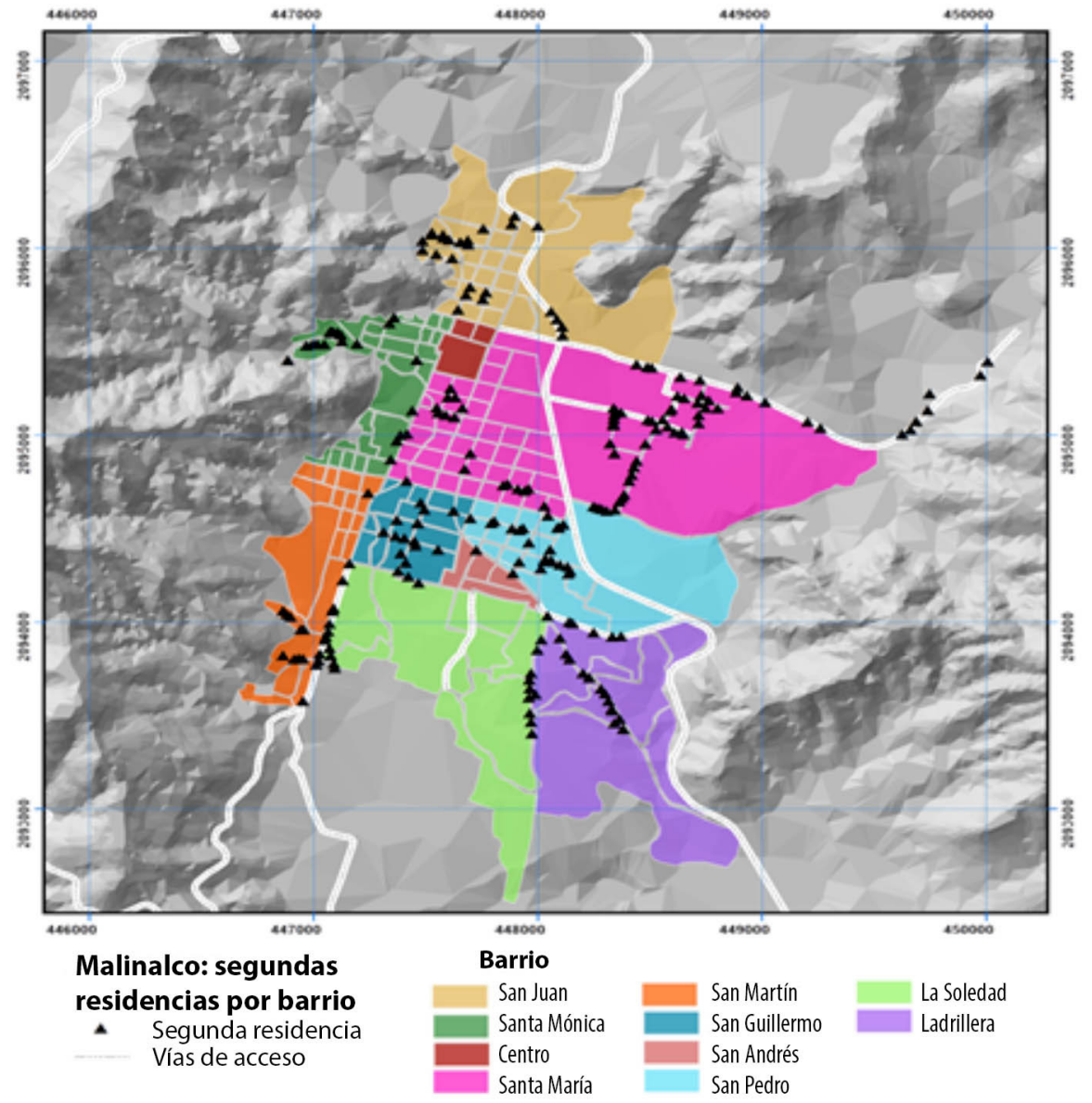

MAPA 2. Ubicación de segundas residencias por barrio 
Segunda fase: el despegue

Se calcula que para el año 2000, las sR en Malinalco alcanzaron las 250 unidades y para el 2004 había unas 50 más (Cestur-Sectur, 2004: 72). Las SR habían proliferado como viviendas unifamiliares independientes, producto de la compra de casas tradicionales o de la adquisición de terrenos y la autoconstrucción de los inmuebles; mayoritariamente mediante trato directo con el propietario original, aunque ya se manifestaba el esquema de los intermediarios. Las casas se presentaban atomizadas y tenían muy diferentes proporciones, ya que habían sido el resultado de un proceso de producción o de remodelación individual, contratando a un arquitecto o un maestro de obras para el efecto.

En función del nivel de influencia del nuevo propietario, las autoridades locales fueron más o menos rígidas en materia de permisos y licencias de construcción pues, por ser asentamiento prehispánico e histórico, muchas de las construcciones del casco urbano se encontraban protegidas por el Instituto Nacional de Antropología e Historia y se requerían permisos y trámites especiales para su adquisición, por esta razón, la construcción de las casas de mayor tamaño se fue realizando en la periferia de la localidad (mapa 2).

El turista residencial típico de ese entonces (Cestur-Sectur, 2004: 108-109) provenía de manera señalada (72\%) del entorno urbano (Distrito Federal y Estado de México), aunque se encontraron algunos que venían de los estados de Morelos, Guerrero, Michoacán, Puebla, Aguascalientes y Coahuila. Las ocupaciones principales registradas fueron empresario y profesionista $(30.8 \%$ cada uno), ubicándose $82 \%$ en los niveles de ingreso de C +, C y A/B. Aún se mantenía el perfil de intelectual o político de alto rango que hubo en un principio, mas, como lo revela la encuesta, en ese tiempo había aparecido el perfil de empresario, algunos de ellos vinculados a los grandes consorcios televisivos en México (en particular a Televisa). Su motivación para adquirir la vivienda se centraba en la cercanía del lugar con su espacio de residencia urbana habitual, que permitía llegar por carretera en un tiempo promedio de una hora y media.

El patrón de viaje establece que la visita se realizaba sobre todo los fines de semana (de jueves o viernes a domingo o lunes), llegando en su mayoría a su vivienda propia (48\%), con un tamaño promedio del grupo de 3.8 personas, visitando el lugar tres veces al año (40\%) o cada mes (16\%), con el propósito de descansar (33\%), propiciar la convivencia familiar (15.2\%) y gozar del 
clima (15.2\%). Los grupos numerosos de turistas residenciales confirmaban que su intención de visita era para la convivencia con amigos y familiares. En este sentido podríamos decir que la actividad principal era la convivencia social privada, rasgo distintivo desde el comienzo de esta modalidad en el destino de Malinalco, al encontrar un ambiente pueblerino de tranquilidad.

A pesar del impulso inicial de TR que tuvo el lugar durante la década anterior, el crecimiento se manifestó lento durante la primera mitad de la década del 2000, pues los atractivos y el prestigio que proporcionaba Malinalco no fueron suficientes para sostener el ritmo de los años anteriores. Fue a partir del 2006, cuando es declarado Pueblo con Encanto, que se observa una revitalización de todas las formas de turismo que se manifestaban en el destino, incluyendo la que aquí estamos tratando, por lo que continuó la construcción de casas de SR bajo el esquema de viviendas unifamiliares independientes. Fue el momento en el que los pobladores aprovecharon para elevar el costo de sus terrenos, ya fuera a través de una negociación directa o por medio de oficinas intermediarias locales.

Para el 2010 se estimó la existencia aproximada de 600 casas de segunda residencia, más del doble de las registradas diez años atrás. Al comparar el crecimiento observado en el transcurso de las cuatro décadas mencionadas es evidente el incremento de las sR durante el periodo de 2000 a 2010 (véase gráfica 1 y cuadro 3).

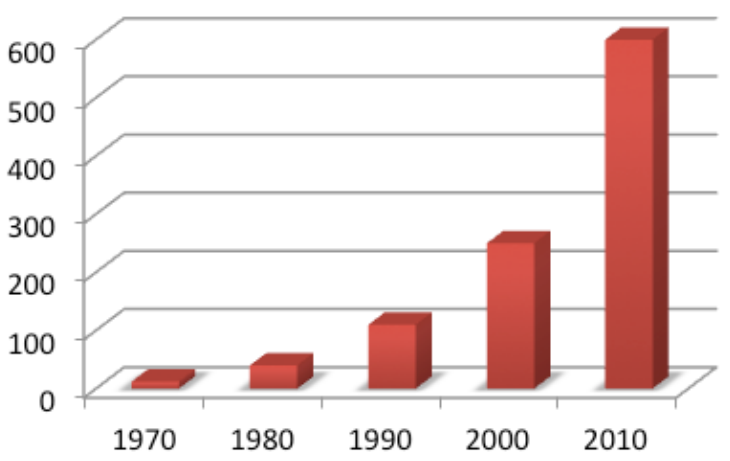

Fuente: Elaboración propia con base en la información de Cestur-Sectur (2004) y Cortés (2014).

GrÁFICA 1. Número de SR en Malinalco 1970-2010 
Cuadro 3. Tasa de crecimiento de las sr en Malinalco 1970-2010

\begin{tabular}{cc} 
Periodo & $\begin{array}{c}\text { Tasa de crecimiento } \\
\%\end{array}$ \\
$1970-1980$ & 233 \\
$1980-1990$ & 175 \\
$1990-2000$ & 127 \\
$2000-2010$ & 140 \\
\hline
\end{tabular}

Fuente: Elaboración propia con base en la información de Cestur-Sectur (2004) y Cortés (2014).

Como puede apreciarse, la tasa de crecimiento del 2000 al 2010 es mayor que la de 1990-2000, lo que confirma el repunte de la dinámica de las sR para ese periodo.

En el mapa 2 se observa la distribución territorial de las sR en el poblado, y es interesante porque ilustra la localización de las SR. Las viviendas de la fase de descubrimiento se localizaron en los barrios de San Juan, Santa Mónica, Santa María y La Ladrillera; además de en esos sitios, en la etapa de despegue, las SR se extendieron a los barrios de San Guillermo, San Pedro, San Andrés, San Martín y La Soledad. En este proceso es posible distinguir un patrón de expansión centro-periferia, puesto que las primeras casas se instalan sobre todo en los barrios que rodean el centro de la población, para después irse ubicando en su periferia sur y este, ocasionando una propagación urbana sobre terrenos anteriormente dedicados a actividades agrícolas.

De acuerdo con Cortés (2014: 72-73), al establecer una relación entre las viviendas totales de la cabecera municipal y las sR, en el año 2000 estas últimas representaban una proporción de 17 \% y para el 2010 la cifra había aumentado a $30 \%$. Otro dato de gran relevancia es aquel que indica que (considerando las 2018 viviendas totales registradas en el 2010 en la localidad de Malinalco, y descartando que de éstas $50 \%$ no contaba con techo de losa) las sR comprenden el $60 \%$ de las viviendas de Malinalco que sí tienen techo de losa (GEM, 2013), lo que pone de manifiesto el elevado contraste que existe entre las condiciones de vivienda de la población residente y las de los turistas residenciales.

En la actualidad, la construcción de sR se registra en el lado sur, entre los barrios de San Martín y La Soledad, y sobre el lado este, en lo que se conoce 
como Llano de Santa María, lugares donde aún hay amplios terrenos sin ningún inmueble. La observación directa constató la construcción de un nuevo fraccionamiento, por lo que en los próximos años el mercado podría redirigirse. Al respecto, Cortés (2014: 74-75) advierte que la expansión de este tipo de alojamiento, si bien ha crecido, no ha llegado a su máximo desarrollo en la localidad, ya que todavía hay extensiones de suelo agrícola disponibles.

Con relación a los entrevistados de las SR, de acuerdo con los resultados obtenidos en el sondeo aplicado, predomina el rango de edad "mayor a 51 años” (40.91\%), seguido de los que se ubican entre 41 y 50 años, así como los de 21 a 30 años (cada uno con 18.18\%). En su gran mayoría, los entrevistados fueron hombres $(77.27 \%)$, casados $(68.17 \%)$, casi en su totalidad mexicanos (95.45\%), y procedentes del Distrito Federal (59.09\%) y el Estado de México (40.91\%), lo que confirma el patrón de demanda proveniente del entorno urbano cercano. El perfil profesional y socioeconómico del turista residencial es el siguiente: empresario o profesionista (cada uno con $27.27 \%$ ), seguidos de ejecutivos (13.64\%), con ingresos familiares mensuales que oscilan entre 30000 y 69000 pesos $(27.27 \%)$ y más de 70000 pesos (18.18\%).

En su comportamiento de viaje, casi todos acuden a Malinalco los fines de semana y permanece un promedio de dos días (77.72\%), otros lo visitan en Semana Santa o en verano ( 9.09 \% cada uno) y en Navidad (4.55 \%). En verano se registra la estancia promedio más prolongada: 25 días; seguida del periodo navideño con un promedio de diez días. La mayoría viaja acompañado de entre una y tres personas $(72.72 \%)$ y entre cuatro y seis $(36.36 \%)$. Tales desplazamientos son motivados con la intención de descansar (77.27 \%) y para reuniones familiares (18.18\%). Estos datos reflejan que se ha acentuado el turista que llega los fines de semana, por sobre los que asisten tres veces al año; además de que el motivo de descanso también se muestra más significativo que en el 2004.

Excepto cuando son acompañados por personas que no conocen el lugar, los turistas permanecen en su residencia la mayor parte del tiempo, saliendo al pueblo solo de manera ocasional para caminar, cabalgar, realizar deportes extremos, adquirir algún artículo no traído de su lugar de residencia habitual, comer en algún restaurante o acudir a misa los domingos, lo que muestra que este tipo de turista tiene poca interacción con la población. El deseo de tener una SR en Malinalco fue alentada por amistades quienes esgrimieron los argumentos 
del clima (36.34 \%) y la tranquilidad del lugar (18.18\%), principalmente, lo cual ratifica que este sitio continúa en un proceso de crecimiento motivado por el estatus y el imaginario de "la casa de campo".

\section{Impactos}

En esta fase (el despegue) del ciclo del destino, se identificaron tres tipos de impactos respecto del TR: los económicos, los ecológicos y los socioculturales.

a) Impactos económicos. Estos se han manifestado al menos en cinco aspectos: el aumento del costo del suelo, la generación de empleos, la diversificación de la economía, la derrama económica y el encarecimiento de productos y servicios para la población.

El costo del suelo, ya se dijo antes, aumentó durante esta fase, y los montos más elevados se concentraron en las áreas que rodean al centro de la población. Excepto en San Guillermo, el costo del suelo en resto de los barrios aumentó en un rango de 100 a 2500 pesos por metro cuadrado.

Cuadro 4. Precios del suelo en la localidad de Malinalco, 2004-2013

\begin{tabular}{|c|c|c|}
\hline \multirow{2}{*}{ Barrio } & \multicolumn{2}{|c|}{ Costo $\mathrm{m}^{2}$} \\
\hline & 2004 & 2013 \\
\hline Centro & $\$ 2000-\$ 4000$ & $\$ 3000-\$ 5000$ \\
\hline Santa Mónica & $\$ 1500-\$ 2500$ & $\$ 3000-\$ 5000$ \\
\hline San Guillermo & $\$ 620-\$ 1000$ & $\$ 620-\$ 1000$ \\
\hline Santa María & $\$ 650-\$ 1500$ & $\$ 750-\$ 2500$ \\
\hline San Juan & $\$ 400-\$ 900$ & $\$ 600-\$ 2000$ \\
\hline El Llano de Santa María & $\$ 350-\$ 450$ & $\$ 500-\$ 1000$ \\
\hline San Martín & $\$ 500-\$ 600$ & $\$ 500-\$ 1000$ \\
\hline La Ladrillera & $\$ 300-\$ 400$ & $\$ 500-\$ 1000$ \\
\hline Jalmolonga (poniente) & $\$ 300-\$ 400$ & $\$ 500-\$ 1000$ \\
\hline
\end{tabular}

Fuente: Elaboración propia con base en entrevista con Rubén Nieto Hernández (2005) y entrevista con Guillermo Miranda Román (13 de septiembre, 2013). 
Al identificar el alto poder adquisitivo de los turistas residenciales, los lugareños optaron por incrementar el precio de sus terrenos y/o casas, alterando el mercado inmobiliario tradicional y limitando la adquisición de una propiedad a sus coterráneos, ya que la oferta es dirigida a personas con un poder adquisitivo muy superior al suyo. Asimismo, las casas pasan de ser residencias principales a secundarias, perturbando la dinámica de habitabilidad, de consumo y de relación vecinal que prevalecía en el poblado.

Por lo que toca a la generación de empleos, los que se vinculan directamente con el TR se presentan en dos rubros: la construcción o remodelación de la vivienda, y el mantenimiento, vigilancia y limpieza del domicilio.

Respecto a la forma de construir o remodelar la residencia, en virtud de que el proceso se realiza por producción individualizada, se identificó que los dueños de las propiedades contratan a profesionales en sus lugares de origen para elaborar los proyectos y/o dirigir las obras, dejando la contratación de los habitantes de Malinalco para la labor de albañilería, aunque en ocasiones también estos trabajadores han sido traídos de fuera, pues los lugareños cobran más que un trabajador contratado en algún otro lugar del estado de México o del Distrito Federal.

Con relación a los empleos que generan las segundas residencias, $68 \%$ de los turistas contrata personal; de estos que contratan trabajadores, $79 \%$ emplea regularmente a dos personas, aunque en una residencia hay siete empleados. A pesar de que los empleados no tienen ningún tipo de contrato, $80 \%$ de los turistas residenciales los asumen como "permanentes" y 59 \% afirma que les proporciona algún tipo de prestación. Los empleos que prevalecen son de carácter informal, dedicados a labores de vigilancia, limpieza y jardinería, con un salario promedio de $\$ 186.00$ diarios, devengados de manera discontinua, en particular los de limpieza, pues dependen de la llegada de los propietarios a la residencia. No obstante el bajo y eventual monto, dicho ingreso resulta significativo ante la situación de pobreza que prima en el municipio, ya que 73 \% de los empleados es originario de Malinalco. Las mujeres se concentran en la limpieza, aunque también se emplean como cocineras y niñeras; los hombres se hacen cargo de la vigilancia y la jardinería.

Al realizar un ejercicio de generalización sobre el número de turistas residenciales que declararon contratar personal para el total de las SR estimadas en 
la población, se alcanzaría una cifra de 730 personas vinculadas a la prestación de un servicio en las sR en Malinalco.

En cuanto a la diversificación económica, podemos decir que, aunque incipiente, se observa que el propio turista residencial ha emprendido el establecimiento de nuevos comercios de venta de ropa, artesanías, alimentos y bebidas (cafeterías y restaurantes), salones de fiestas y constructoras, mismos que, a excepción de los dos últimos, abren los fines de semana y periodos vacacionales, lo que indica que tales establecimientos están dirigidos a los visitantes más que a la población. De acuerdo con el sondeo, 18 \% de los turistas residenciales ha emprendido un negocio, aunque las autoridades municipales estiman que $5 \%$ del total de ellos cuenta con una empresa o comercio, introduciendo productos como carnes y quesos, que poco se consumen entre los habitantes de la localidad. Este consumo abre nuevas vertientes dentro de la economía local.

La derrama económica que el turista residencial hace en la población es muy poca y va de 2001 a 3000.00 pesos (40.90\%), seguido del rango de aquellos que gastan más de 5000 pesos (22.73\%); dicho gasto se destina en esencia a las compras complementarias para la preparación de alimentos (32\%), al mantenimiento de la vivienda (27\%) y al consumo en restaurantes $(27 \%)$. Es evidente que la derrama para la localidad es escasa y se vincula con los empleos informales, los consumos en restaurantes y la compra de algunos víveres, pues la mayoría de estos los traen los turistas residenciales del lugar en el que viven cotidianamente.

Es importante anotar que el Ayuntamiento también obtiene un ingreso derivado de los permisos de construcción, del impuesto predial y de las conexiones y suministros de agua y drenaje de las sR. Según los cálculos que resultaron de la investigación, alrededor de $30 \%$ de los ingresos obtenidos por el gobierno municipal por estos conceptos proviene de ellas.

El desarrollo del TR en Malinalco ha traído como consecuencia para la población el encarecimiento de la vida, es decir, la elevación de precios en productos y servicios tales como la renta de casas habitación y la luz, entre otros. Uno de los entrevistados comentó que hace diez años (justamente en el 2004), era bastante sencillo para mucha gente rentar una casa o un cuarto, porque era barato, ahora es muy caro y cada vez es más difícil. Por ejemplo, una familia que antes pagaba un recibo de luz de 300 pesos, ahora lo paga en 1 200, y, a pesar de las protestas, 
la Comisión Federal de Electricidad ( $\mathrm{CFE}$ ) no realiza ninguna distinción entre viviendas de habitantes y de turistas residenciales.

b) Impactos ecológicos. Aunque no se dispone de información precisa sobre el consumo de agua del turista residencial, es claro que su requerimiento promedio sobre el vital líquido es mayor al de los habitantes permanentes, puesto que la mayoría de sus casas cuentan con cisterna para asegurarse el abastecimiento y la dotación necesaria para el llenado de las albercas y el mantenimiento de los jardines. Lo anterior en detrimento del suministro que regularmente tiene la población. Asimismo, se registraron al menos dos casos en los que la propiedad de los turistas residenciales contenía la posesión de un arroyo o manantial de donde antes se abastecían los lugareños para los cultivos. Esto generó conflictos hasta que se alcanzaron acuerdos favorables para los locales, a partir de la presión ejercida por ellos sobre los turistas.

Por lo que toca a los impactos ecológicos derivados directamente del tr, se encontró que, con la intención de embellecer los jardines de las casas de sr, se han introducido nuevas especies de plantas ajenas a la vegetación local. Lo anterior, aunado a la desaparición de las antiguas huertas, convertidas ahora en jardines, está provocando una alteración o desaparición de flora y fauna de la región, modificando poco a poco los ecosistemas, lo que muy probablemente provocará un aumento de la temperatura en un corto plazo, sobre todo por la usencia de árboles.

Otro cambio observado fue la incorporación de ciertas prácticas sustentables por parte de los turistas residenciales: uso de focos ahorradores $(77.26 \%)$, colecta de agua de lluvia (45.45\%) y la separación de residuos (31.82 \%). Además se identificó un incipiente uso de tecnologías verdes: calentadores solares, focos tipo led y tecnología de bajo consumo en equipos de aire acondicionado y refrigeradores.

c) Impactos socioculturales. El contacto entre la población y los turistas residenciales es mínimo, ya que a estos últimos no les agrada participar en las fiestas patronales, ni en las costumbres y tradiciones de los lugares. Así lo hizo saber el cronista municipal (25 de octubre de 2013): "son personas que no les gustan nuestras fiestas, no les gusta el ruido, no les gusta oír las campanas, ni los cohetes, ellos vienen a descansar y cuando salen de sus casas no platican con la gente del pueblo”. No obstante, el turista residencial suele aportar la cooperación que le 
es solicitada por las mayordomías de los barrios para las celebraciones religiosas, que son de gran arraigo entre la población, aunque no participen en las actividades ni en las ceremonias.

Con relación al patrimonio cultural, el turismo residencial ha tenido una participación contrastante de preservación y de destrucción. Por un lado, el perfil de intelectual de determinados turistas, ha contribuido al rescate y mantenimiento de bienes culturales muebles e inmuebles, como las acciones emprendidas por el Patronato formado para restaurar el exconvento Agustino del Divino Salvador, del siglo xvi; pero, por otro lado, algunas casas fueron construidas sobre vestigios arqueológicos, destruyendo importantes evidencias no solo prehispánicas, sino incluso prehistóricas, como lo declaró el arquitecto Nieto en entrevista celebrada el 9 de julio de 2014.

Otro fenómeno que sobresale es el poco deseable aumento de la delincuencia, ya que los informantes clave confirmaron que existen grupos organizados de delincuentes que asaltan las casas de los turistas residenciales, atracando también a los turistas convencionales, lo cual afecta a toda la corriente de visitantes que acude al lugar.

\section{Conclusiones}

El desarrollo de la actividad turística en Malinalco ha provocado transformaciones físico-naturales y socioeconómicas en la última década, en la que el TR ha tenido una participación significativa. El proceso de terciarización que muestra el municipio está ligado al crecimiento del turismo y a la sensible disminución de la actividad agropecuaria y, aunque esta demarcación rural se ha clasificado en un nivel medio de marginación, las actuales dinámicas económica y social no han modificado las condiciones de pobreza de la mayoría de los habitantes (más graves que el promedio nacional y estatal). Es decir, el crecimiento turístico no ha generado aún el suficiente desarrollo para que mejoren las condiciones de vida de la población.

En este marco, el TR es el segmento que mayor impacto tuvo en el cambio de vocación del suelo y en la mutación del espacio agrario a turístico, particularmente a partir del año 2005, cuando las sR crecen hasta superar el doble del volumen que tenían al iniciar el presente siglo. El modelo de mercantilización inmobiliaria 
se ha mantenido atomizado y sujeto a tratos directos o a intermediaciones locales, circunstancia que se considera causal de la moderada cantidad de sR que existen, comparado con otros sitios del interior. No obstante, el destino todavía no alcanza su tope máximo de desarrollo, por lo que se prevé que siga creciendo lentamente bajo este esquema, aunque no se descarta la posibilidad de que surja un mercado inmobiliario tipo fraccionamiento que acelere la densidad de las SR.

Ante la falta de un mercado inmobiliario estructurado, el esquema de autoconstrucción individual y su resolución independiente ha producido también una dispersión de las SR y una mezcla con las casas de los habitantes permanentes, lo que conlleva un desplazamiento de población original por población externa en los barrios tradicionales. A largo plazo, si dichas casas se convierten de habitabilidad temporal a permanente, el proceso de diferenciación en los estilos de vida entre unos y otros será más acentuado, y acrecentará la desigualdad respecto de la población original.

Para el caso de la demanda, el comportamiento de residentes nacionales con excedentes económicos que eligen a este sitio como lugar de descanso se mantuvo como el principal nicho de mercado en ambas fases del proceso del TR, motivado por el estatus y el imaginario de "la casa de campo", con todo, de la etapa de descubrimiento a la de despegue se observan pequeñas diferencias: del perfil de un turista intelectual y culto se abre el abanico a turistas empresariales y ejecutivos, con mayor apego al descanso privado y a los negocios que a las prácticas culturales. También se incrementa la práctica de los viajes de fines de semana por sobre los de temporadas vacacionales, condicionados muy probablemente por el estrés de la vida urbana metropolitana. El aislamiento es otro elemento que se generaliza en los turistas residenciales, al privilegiar la convivencia social con la familia y los amigos por sobre la visita a los atractivos o la interacción con los habitantes del lugar.

Una característica que merece la pena resaltarse es que los propietarios de SR tienden a la tercera edad, por lo que el fenómeno de migración puede presentarse de manera significativa en una década más.

Por lo que se refiere a los impactos observados en el sitio, la mayoría son similares a los documentados en otras investigaciones sobre el tema del TR: el encarecimiento de la vida cotidiana por el alza de terrenos, servicios y productos de consumo; el cambio en el uso de suelo pasando de un uso predominantemente 
agrícola (ocupado por la casa-huerta) al uso habitacional de tipo residencial; y los contrastes en materia de sustentabilidad, por el cambio en los ecosistemas y el mayor consumo promedio de agua (entre los aspectos negativos), y la introducción de prácticas ambientales y tecnologías verdes (entre los factores positivos). Sin embargo un comportamiento distintivo, resultado del particular esquema de producción inmobiliaria que se presenta en Malinalco, es que la mayor cantidad de empleos potenciales no está en la construcción, sino en los servicios de vigilancia y mantenimiento, trabajos que tienen mayor permanencia y benefician de forma directa a los lugareños de baja cualificación, tanto hombres como mujeres.

\section{Fuentes citadas}

Alarcón, P., E.M. González y J.R. Pérez (2010). "Residential Tourism in the South of Spain: An Approach towards Consumption”. Encontros Cientificos-Tourism \& Management Studies, 6, 36-48.

Aledo, A. (2008). “De la tierra al suelo: La transformación del paisaje y el nuevo turismo residencial”. Arbor. Ciencia, Pensamiento y Cultura, CLXXXIV (729), 99-113.

Aledo, A., H. García y G. Ortiz (2010). "Análisis de mapas causales de impactos del turismo residencial”. Empiria. Revista de Metodología de Ciencias Sociales, 20, 61-68.

Aledo, A., T. Mazón y A. Mantecón (2007). "La insostenibilidad del turismo residencial”, en D. Lagunas (coord.). Antropología y turismo: claves culturales y disciplinares. México: Plaza y Valdés, 185-208.

Almeida, F. y D. López (2003). "La Costa del Sol Oriental: un conflicto territorial entre el turismo, la agricultura y la urbanización metropolitana”. Baética. Estudios de Arte, Geografía e Historia, 25, 67-80.

Benson, M. y K. O’Reilly (2009). "Migration and the Search for a Better Way of Life: A Critical Exploration of Lifestyle Migration”. The Sociological Review, 57 (4), 608-625.

Cañada, E. (2010). Turismo en Centroamérica, nuevo escenario de conflicto social. Managua: AlbaSud.

Casado-Díaz, M.Á., C. Kaiser y A. Warnes (2004). “Northern European Retired Residents in Nine Southern European Areas: Characteristics Motivations and Adjustment”. Ageing and Society, 24 (3), 353-381. 
Cestur-Sectur (2004). El turismo de segundas residencias en México. México: Centro de Estudios Superiores en Turismo/Secretaría de Turismo Federal.

Coles, T., D. Duval y M. Hall (2005). "Sobre el turismo y la movilidad en tiempos de movimiento y conjetura posdiciplinar”. Política y Sociedad, 42 (2), 181-198.

Conapo (2012). "Delimitación de las zonas metropolitanas de México 2010 Análisis de resultados" [en línea]. Consejo Nacional de Población. Disponible en: http://www.conapo.gob.mx/es/CONAPO/Delimitacion_de_las_zonas_metropolitanas_de_Mexico_2010_-_Analisis_de_resultados [2014, 11 de julio].

Coneval (2010). “Medición de la pobreza. Pobreza a nivel municipio 2010” [en línea]. Consejo Nacional de Evaluación de la Política de Desarrollo Social. Disponible en: http://www.coneval.gob.mx/Medicion/Paginas/ Medici\%C3\%B3n/Medicion-de-la-pobreza-municipal-2010.aspx [2014, 4 de mayo].

Cortés, I. (2014). "Factores de localización de las segundas residencias en la localidad de Malinalco, Estado de México". Tesis de maestría. Toluca: Universidad Autónoma del Estado de México.

Díaz, F. y M.L. Lourés (2006). Housing, Tourism and the Real Estate Sector: The Spanish Mediterranean Coast. Alicante: Universidad de Alicante.

Faulkenberry, L.V. et al. (2000). "A Culture of Servitude: The Impact of Tourism and Development on South Carolina's Coast”. Human Organization, 59 (1), 86-95.

Fernández, S. y D. Barrado (2011). "El desarrollo turístico inmobiliario de la España mediterránea e insular frente a sus referentes internacionales (Florida y la Costa Azul): un análisis comparado". Cuadernos de Turismo, 27, 373-402.

Fundación BBva Bancomer (2012). “Los 'Baby Boomers' de eEuU en México: un grupo creciente de migrantes” [en línea]. Análisis Económico Bвva Research Flash, 21 de marzo. Disponible en: https://www.fundacionbbvabancomer.org/imagenes/docs/120321_flashmigracionmexico.pdf

García, A., A. Artal y J.M. Ramos (2002). "El turismo del mar menor: predominio de la segunda residencia”. Cuadernos de Turismo, 9, 33-43. 
GEM (1999). Historia de Malinalco. Toluca: Gobierno del Estado de México.

------ (2009). Plan de Desarrollo Municipal de Malinalco, Méx. 2009-2012. Toluca: Gobierno del Estado de México.

------ (2012). Programa Regional Ixtapan de la Sal 2012-2017. Toluca: Gobierno del Estado de México.

------ (2013). Plan de Desarrollo Municipal de Malinalco, Méx. 2013-2017. Toluca: Gobierno del Estado de México.

Guilding, C. et al. (2005). "An Agency Theory Perspective on the Owner/Manager Relationship in Tourism-Based Condominiums". Tourism Management, 26 (3), 409-420.

Gili, M. (2003). “Las viviendas de segunda residencia. ¿Ocio o negocio?” Scripta Nova. Revista Electrónica de Geografía y Ciencias Sociales, VII (146).

Hall, C.M. y D.K. Müller (2004). Tourism, Mobility, and Second Homes: Between Elite Landscape and Common Ground. Clevedon: Channel View Publications.

Hidalgo, R. y H.M. Zunino (2011). “Negocios inmobiliarios en centros turísticos de montaña y nuevos modos de vida”. Estudios y Perspectivas en Turismo, 20 (2), 307-326.

Hiernaux, D. (2005). "La promoción inmobiliaria y el turismo residencial: el caso mexicano”. Scripta Nova. Revista Electrónica de Geografía y Ciencias Sociales, IX (194), 1 de agosto.

------ (2009). "Los imaginarios del turismo residencial: experiencias mexicanas”, en T. Mazón, R. Huete y A. Mantecón (eds.). Turismo, urbanización y estilos de vida. Las nuevas formas de movilidad residencial. Barcelona: Icaria, 109-125.

Hiernaux, D. (coord.) (2010). Las segundas residencias en México: Un balance. México: Plaza y Valdés.

Huete, R. (2008). “Tendencias del turismo residencial: El caso del Mediterráneo español”. Periplo Sustentable, 14, julio, 65-87.

------ (2010). "Opiniones y actitudes ante el turismo residencial en el sur de la Comunidad Valenciana”. Pasos. Revista de Turismo y Patrimonio Cultural, 8 (4), 445-461.

Huete, R. y A. Mantecón (2010). "Los límites entre el turismo y la migración residencial. Una tipología”. Papers, 95 (3), 781-801. 
(2012). "Residential Tourism or Lifestyle Migration. Social Problems Linked to the non-Definition of the Situation”, en O. Moufakkir y P. Burns (eds.). Controversies in Tourism. Wallingford: Centre for Agricultural Bioscience International, 160-173.

Huete, R., A. Mantecón y T. Mazón (2008). “¿De qué hablamos cuando hablamos de turismo residencial?”. Cuadernos de Turismo, 22, 101-121.

InEgi (2000). XII Censo General de Población y Vivienda. México: Instituto Nacional de Estadística, Geografía e Informática.

------ (2005). II Conteo de Población y Vivienda. México: Instituto Nacional de Estadística y Geografía e Informática.

------ (2010). Censo de Población y Vivienda 2010. México: Instituto Nacional de Estadística y Geografía.

Lizárraga, O. (2010). “The US Citizens Retirement Migration to Los Cabos, México. Profile and Social Effects". Recreation and Society in Africa, Asia and Latin America, 1 (1), 75-92.

López de Lera, D. (1995). "La inmigración en España a fines del siglo xx. Los que vienen a trabajar y los que vienen a descansar”. Revista Española de Investigaciones Sociológicas, 71-72, 225-245.

Mantecón, A. y R. Huete (2011). "Sociological Insights on Residential Tourism: Host Society Attitudes in a Mature Destination”. European Journal of Tourism Research, 4 (2), 109-122.

Martínez, F.J., A.J. Pauls y J. Solsona (2003). "Las viviendas familiares y su uso turístico en la comunidad Valenciana”. Estudios Turísticos, 155156, 159-177.

Mazón, T. (2006). "El turismo litoral mediterráneo: ipolíticas turísticas o desarrollo inmobiliario?”, en J.A. Rodríguez (ed.). Sociología para el futuro. Barcelona: Icaria, 301-310.

Mazón, T. y A. Aledo (2005). "El dilema del turismo residencial: ¿turismo o desarrollo inmobiliario?”, en T. Mazón y A. Aledo (eds.). Turismo residencial y cambio social. Nuevas perspectivas teóricas y empíricas. Alicante: Universidad de Alicante/Aguaclara, 13-30.

Mazón, T., R. Huete y A. Mantecón (2009). “Tourism Dependence and Host Community Perceptions. Notes on the Social Exchange Theory". Encontros Científicos-Tourism \& Management Studies, 5, 25-36. 
Müller, D. (2002). "German Second Homeowners in Sweden. Some Remarks on the Tourism - Migrations - Nexus”. Revue Européene des Migrations Internationals, 18 (1), 67-86.

Nielsen, K. (2009). "La migración internacional de europeos retirados y el turismo de la tercera edad: el caso de la Costa del Sol”, en T. Mazón, R. Huete y A. Mantecón (eds.). Turismo, urbanización y estilos de vida. Las nuevas formas de movilidad residencial. Barcelona: Icaria, 285-300. O’Reilly, K. (2007). "Emerging Tourism Futures: Residential Tourism and its Implications”, en C. Geoffroy y R. Sibley. Going Abroad. Travel, Tourism and Migration. Newcastle: Cambridge Scholars Publishing, 144-157.

------ (2009). "Hosts and Guests, Guests and Hosts: British Residential Tourism in the Costa del Sol”, en P. Obrador Pons, M. Crang y P. Travlou (eds.). Cultures of Mass Tourism: Doing the Mediterranean in the Age of Banal Mobilities. Farnham: Ashgate, 129-142.

O’Reilly, K. y M. Benson (eds.) (2009). Lifestyle Migrations: Escaping to the Good Life. Loughborough: Loughborough University.

Palma, M. (2005). "Asociaciones de inmigrantes extranjeros en la Ciudad de México. Una mirada a fines del siglo xx”. Migraciones Internacionales, 3 (2), julio-diciembre, 29-57.

Ramón, A. y P. Taltavull (2005). “Turismo y viviendas”. Economistas, 103, 6880.

Raya Mellado, P. (dir.) (2001). Turismo residencial en Andalucía. Sevilla: Consejería de Turismo y Deportes de la Junta de Andalucía.

Rodríguez, V. (2004). “Turismo residencial y migración de jubilados”. Mediterráneo Económico, 5, Las Nuevas Formas del Turismo, 233-253.

Salvà, P.A. (2005). "Procesos, pautas y tendencias del turismo residencial en las Islas Baleares: ¿inmigrantes de lujo o turistas de larga estancia?”, en T. Mazón y A. Aledo (eds.). Turismo residencial y cambio social. Nuevas perspectivas teóricas y empíricas. Alicante: Universidad de Alicante/ Aguaclara, 281-302.

------ (2011). “El turismo residencial ¿una manifestación de nuevos turismos y nuevos comportamientos turísticos en el siglo xxı?". Cuadernos de Turismo, 27, 823-836.

Sanz, S. (2008). "Imagen global e intenciones futuras del comportamiento del 
turista de segunda residencia”. Revista Europea de Dirección y Economía de la Empresa, 17 (4), 95-114.

Schneider, L.M. (1999). Malinalco. Monografía municipal. Toluca: Gobierno del Estado de México.

Sectur (2012). Anuario estadístico 2011. Toluca: Secretaría de Turismo del Estado de México.

(2014). Directorio de servicios de alojamiento turístico en Malinalco. Toluca: Secretaría de Turismo del Estado de México.

Serrano Martínez, J.M. (2003). "Las viviendas de segunda residencia en la sociedad del 'bienestar'. El caso de un país turístico: España”. Cuadernos de Turismo, 12, 53-75.

Torres, E. (2003). "El turismo residenciado y sus efectos en los destinos turísticos”. Estudios Turísticos, 155-156, 45-70.

Urbain, J.-D. (2002). Sur la plage. París: Payot (Petite Bibliotheque Payot).

Van Noorloos, F. (2009). "Residential Tourism in Coastal Areas: Consequences for Local Development in Nicaragua and Costa Rica”. Presentación para el $15^{\text {th }}$ Annual International Sustainable Development Research Conference, Utrecht, 5-8 de julio.

Varela, B., A. López y A. Martínez (2003). "Primeras aproximaciones al estudio estadístico del alojamiento privado con fines turísticos desde una perspectiva de oferta”. Estudios Turísticos, 155-156, 87-109.

Warnken, J. y C. Guilding (2009). "Multi-Ownership of Tourism Accommodation Complexes: A Critique of Types, Relative Merits, and Challenges Arising”. Tourism Management, 30 (5), 704-714.

Williams, A.M. y C.M. Hall (2000). "Tourism and Migration: New Relationships between Production and Consumption”. Tourism Geographies: An International Journal of Tourism Space, Place and Environment, 2 (1), 5-27. http://doi.org/10.1080/146166800363420 